Earth Interactions - Volume 14 (2010) - Paper No. 19 • Page 1

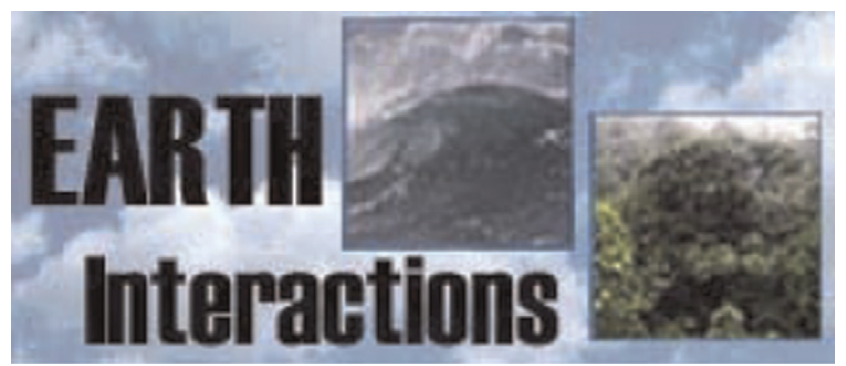

Copyright (C 2010, Paper 14-019; 8397 words, 5 Figures, 0 Animations, 2 Tables.

http://EarthInteractions.org

\title{
Using Tree Rings to Predict the Response of Tree Growth to Climate Change in the Continental United States during the Twenty-First Century
}

\section{A. Park Williams* and Joel Michaelsen}

Geography Department, University of California, Santa Barbara, Santa Barbara, California

\section{Steven W. Leavitt}

Laboratory of Tree-Ring Research, University of Arizona, Tucson, Arizona

\section{Christopher J. Still}

Geography Department, University of California, Santa Barbara, Santa Barbara, California

Received 16 June 2010; accepted 15 September 2010

\begin{abstract}
In the early 1900s, tree-ring scientists began analyzing the relative widths of annual growth rings preserved in the cross sections of trees to infer past climate variations. Now, many ring-width index (RWI) chronologies, each representing a specific site and species, are archived online within the International Tree-Ring Data Bank (ITRDB). Comparing annual tree-ringwidth data from 1097 sites in the continental United States to climate data, the authors quantitatively evaluated how trees at each site have historically responded to interannual climate variations. For each site, they developed a climate-driven statistical growth equation that uses regional climate variables to
\end{abstract}

* Corresponding author address: A. Park Williams, Geography Department, University of California, Santa Barbara, 1832 Ellison Hall, Santa Barbara, CA 93106-4060.

E-mail address: williams@geog.ucsb.edu 
Earth Interactions - Volume 14 (2010) - Paper No. 19 • Page 2

model RWI values. The authors applied these growth models to predict how tree growth will respond to twenty-first-century climate change, considering four climate projections. Although caution should be taken when extrapolating past relationships with climate into the future, the authors observed several clear and interesting patterns in the growth projections that seem likely if warming continues. Most notably, the models project that productivity of dominant tree species in the southwestern United States will decrease substantially during this century, especially in warmer and drier areas. In the northwest, nonlinear growth relationships with temperature may lead to warming-induced declines in growth for many trees that historically responded positively to warmer temperatures. This work takes advantage of the unmatched temporal length and spatial breath of annual growth data available within the ITRDB and exemplifies the potential of this ever-growing archive of tree-ring data to serve in meta-analyses of large-scale forest ecology.

KEYWORDS: Tree rings; Climate change; Forests; United States

\section{Introduction}

Climate change is expected to cause dramatic shifts in vegetation growth rates and distributions during the twenty-first century (Overpeck et al. 1990; Innes 1991; Sala et al. 2000; Davis and Shaw 2001; Walther et al. 2002; Root et al. 2003; Thomas et al. 2004; Boisvenue and Running 2006; Bernstein et al. 2007). As global temperatures warm, some of the largest impacts are expected to occur in arid regions where plants grow in a semipermanent state of drought stress (Allen and Breshears 1998; Breshears et al. 2005; Bernstein et al. 2007; van Mantgem et al. 2009). Within the continental United States, average annual temperatures increased during the twentieth century by about $0.65^{\circ} \mathrm{C}$ (Di Luzio et al. 2008), in line with the global mean temperature trend (Bernstein et al. 2007). The geographic distribution of climate change, however, was far from uniform within the continental United States. Although warming was most significant in the western United States, many areas within the west experienced no change or even slight cooling. Furthermore, climate trends during the twentieth century varied greatly depending upon the portion of the century considered. Spatial and temporal heterogeneity in climate change has made it difficult to understand and predict how ecosystems throughout the United States will respond to a changing climate.

Beyond this variation in climate trends, vegetation responses to climate change will vary by species and geography. For example, plants that are predominantly drought limited may benefit from cooling, whereas plants limited by winter freezes may benefit from warming. Of course, temperature is not the sole driver of plant growth, nor is it the only climate variable that is changing. Average annual precipitation across the continental United States increased by roughly $8 \%$ during the twentieth century, and average relative humidity increased at a rate of about $0.5 \%$ decade $^{-1}$ since the 1950s (Di Luzio et al. 2008). Such increases would presumably benefit drought-stressed plants in the absence of large temperature increases. Throughout most of the arid regions of the western United States, temperatures increased throughout the century. Temperature increases in the west accelerated during the past three decades and were accompanied by decreases in precipitation and relative humidity, further stressing vegetation in these regions.

Among plant functional types possibly affected by climate change, trees are of particular concern. Changes in their growth and related ecological processes (e.g., 
Earth Interactions - Volume 14 (2010) • Paper No. 19 • Page 3

recruitment, growth rate, mortality) can rapidly drive long-term modifications to ecosystem type; water and carbon cycling rates; and surface properties such as erosivity, albedo, snowmelt dynamics, and wind turbulence (Bernstein et al. 2007). Within populations, changes in productivity are expected to be most rapid and measurable at and near ecotones, the boundaries between ecosystems (Holland et al. 1991; Gosz 1992; Risser 1995; Pitelka 1997; Allen and Breshears 1998; Van de Ven et al. 2007; Fischer et al. 2009; Purves 2009). This suggests that range boundaries of many tree species are likely to adjust in response to climate change.

Thus far, climate-induced forest die-off events have primarily been observed in case studies focusing on specific species and regions of interest (Allen and Breshears 1998; Breshears et al. 2005; Allen et al. 2010). Although some case studies have successfully established how specific tree populations have responded to specific climatic disturbances, they typically focus on spatial scales that are too small to provide reliable insight into how forests might respond to climate change on larger spatial scales. In combating the problem of spatial scale, the U.S. Department of Agriculture (USDA) Forest Inventory and Analysis program now collects a vast amount of forest growth data annually throughout the United States. After several decades of regular data collection, this dataset will likely provide more information regarding forest response to climate change than any dataset currently available. Studies that use satellite imagery to monitor growth dynamics across large geographic areas are also promising (Hicke et al. 2002; Running et al. 2004; Lapenis et al. 2005; Hansen et al. 2010). Like forest inventory data though, satellite technology is still young and imagery records are short. Further, trends in productivity are difficult to quantify using satellite-derived spectral estimates of relative greenness, liquid water storage, and leaf area.

Conveniently, many extratropical trees have been growing for hundreds or even thousands of years while annually recording growth data in the width of the annual growth rings in their trunks. Wide rings generally grow during years of optimal climatic conditions and narrow rings occur in response to poor conditions (Babbage 1838; Douglass 1909; Fritts 1976; Hughes et al. 2009). Because of the well-established relationship between ring width and climate, tree-ring scientists have collected cross sections of trees and developed time series of tree-ring widths for many species at thousands of sites globally. Many of these records of annual tree-ring widths are archived by the National Climate Data Center (NCDC) in the International Tree-Ring Data Bank (ITRDB; available online at http://www.ncdc.noaa.gov/paleo/treering.html; Grissino-Mayer et al. 1993).

To date, several studies have inferred forest response to future climate change from statistical relationships between tree-ring-width records and past climate variability. For example, D.L. Peterson and associates exhaustively collected and analyzed tree-ring data from many sites to determine the climate variables governing annual growth for various conifer species across a number of climate regimes in the montane Pacific Northwest (Ettl and Peterson 1995; Peterson and Peterson 2001; Peterson et al. 2002; Holman and Peterson 2006; Nakawatase and Peterson 2006). Across a broader geographic range, McKenzie et al. (McKenzie et al. 2001) inferred increases in annual growth rates since 1850 at some highelevation and high-latitude sites in an analysis of 150 ring-width records from western North America. More recently, Williams et al. (Williams et al. 2010) focused on a portion of the southwestern United States, mainly encompassing 
Earth Interactions - Volume 14 (2010) • Paper No. 19 • Page 4

Arizona and New Mexico, and showed that ITRDB ring-width records from this region exhibit unique drought sensitivity compared to records from elsewhere in the continental United States. Although tree-ring-width chronologies within the ITRDB were collected from nonrandom populations (trees are often sampled because they are believed to be particularly sensitive to climate), no other dataset containing annual growth information across such a broad geographical, temporal, or taxonomic range is currently available. In this light, McKenzie et al. (McKenzie et al. 2001) and Williams et al. (Williams et al. 2010) represent novel uses of the best tree growth data available to search for important ecological responses to large-scale climate change.

Here, we build upon these studies by testing the hypothesis that many tree-ringwidth chronologies from the ITRDB can be used to reasonably project how climate change may impact future forest growth at many sites within the continental United States. We evaluated relationships between ring widths and seasonal climate at each of 1097 sites. Considering seasonal climate records as potential predictors of annual ring widths, we used a stepwise linear regression approach to model annual ring-width index (RWI) values at each site. We then assumed four unique twentyfirst-century climate scenarios and used the growth equations to predict twentyfirst-century annual RWI values at each site. We compared predicted future RWI values to those of the past and identified sites where forest growth rates are likely to decline.

\section{Methods}

\subsection{Tree-ring data}

We obtained 1148 RWI chronologies from sites within the continental United States listed by the ITRDB in September 2009, as well as four unpublished chronologies. Each chronology represents the average of multiple trees at a site (usually more than 10). As opposed to raw ring widths, RWI values were used for each site because they are standardized to preserve interannual variability and remove long-term trends caused by aging and increasing trunk diameter (Cook et al. 1990). Standardization typically increases the proportion of interannual variability in ring-width values that can be explained by climate. RWI values do not translate to absolute measurements of productivity or growth rate. They represent relative radial growth rates fluctuating around a common mean RWI value of 1.0. An RWI value of 2.0 represents a year when radial growth was twice that of a normal year. An RWI of 0.5 represents half that of a normal year. Rather than standardize raw ring-width records ourselves using a uniform approach for all chronologies, we used the standardized index chronologies provided by the ITRDB contributors. Methods of standardization varied among chronologies and were generally developed by individuals who carefully considered how to best standardize each individual ring-width record using a certain amount of expertise on the site and the sampled population. See Williams et al. (Williams et al. 2010, supporting information section) for a more detailed explanation of standardization issues. Williams et al. also demonstrate that, although standardization inherently removes low-frequency variability from ring-width records, weakening low-frequency relationships with climate, the vast majority of RWI records used 


\section{Earth Interactions - Volume 14 (2010) • Paper No. 19 • Page 5}

in this study still reflect climate variability occurring on time scales of 5060 years.

To increase the probability that each RWI record represents the productivity of numerous trees, we only considered RWI values that were calculated using at least five tree cores. Notably, the ITRDB only clarifies how many cores, not how many trees, are represented in each chronology; commonly, however, two cores are collected from each tree. We only considered chronologies with at least 60 RWI values (years) after 1895 so that we could evaluate statistical relationships between ring-width indices and climate data that began in fall 1895. Ring-width records fit these criteria at 1097 sites.

\subsection{Climate data}

We obtained monthly gridded climate data (total precipitation and average daily maximum, minimum, and dewpoint temperature) for 1895 through 2008 from the Parameter-elevation Regressions on Independent Slopes Model (PRISM) group at Oregon State University. PRISM data are grids with 2.5 arc min $(\sim 4 \mathrm{~km})$ spatial resolution. For each tree-ring site, we averaged the records of the nine grid cells (3 by 3 ) centered on the reported site because the locations of the sites were not always precisely reported. Using the monthly data at each site, we calculated seasonal records for each of the four 3-month seasons, beginning with fall (October through December) and ending with summer (July through September). Therefore, each year's climate began in the fall of the previous year.

\subsection{Growth modeling}

We used multiple linear regression analysis to create a climate-based growth equation for each of the 1097 RWI records independently. Growth is often most responsive to a given climate parameter during a certain portion of the year, and the growth response may be positive or negative depending on the time of year. We evaluated the effect of each of the four climate variables during each of four 3 -month seasons over a 12-month period that begins in October and ends in September (4 climate parameters $\times 4$ seasons $=16$ variables).

To reduce the probability of using climate variables that are not mechanistically associated with tree growth, we only incorporated a given climate variable in a growth model if it made a "substantial contribution" to the predictability of RWI. To do this, we conducted a forward stepwise regression. During this process, we only included

predictors that improved the coefficient of determination $\left(R^{2}\right)$ of the model by more than 0.02 . The majority of models incorporated three to five climate variables.

Even using the rather conservative stepwise approach toward model development, statistical models developed from many potential predictors always run a substantial risk of being overfit because spurious relationships between ring widths and climate are bound to occur occasionally. To decrease this risk, we used cross validation to evaluate the true predictive power of the each of the 1097 growth models. Cross validation involves sequentially removing one RWI value at a time, calculating new growth equations using the climate and RWI data from all other years, and predicting the missing RWI value. The correlation coefficient yielded by 
Earth Interactions - Volume 14 (2010) • Paper No. 19 • Page 6

correlating the new cross-validated RWI record with the actual record is more representative of each model's true predictive power because each cross-validated RWI value was calculated using a model developed with independent data (Michaelsen 1987).

Cross-validated correlation of modeled and actual RWI records produced a $p$ value of less than 0.01 (99\% significance) for 963 of the 1097 records evaluated. A $p$ value calculated in this study, however, underestimates the true probability of a false statistical relationship between modeled and actual ring widths because each growth model had more than one opportunity to include a false but statistically present relationship during the stepwise process. We therefore limited all projections of twenty-first-century growth to the 853 sites where modeled and actual RWI values correlated with a cross-validated $p$ value of less than $0.001(99.9 \%$ significance). Although significance tests are not technically valid for cross-validated correlations, we feel that using such a strict standard for model acceptability sufficiently minimized the risk of using growth models that incorporated false relationships between growth and climate.

Importantly, climate can affect tree growth over more than just one growing season. Physiological and stand-dynamics effects unrelated to climate can also affect growth over multiple consecutive growing seasons. These low-frequency effects on tree growth often cause autocorrelation within RWI records. To isolate only year-to-year variability in the ring-width record, this autoregressive component is often removed prior to analysis in tree-ring studies (Meko and Graybill 1995). After extensive testing, we determined that removing the autoregressive component from RWI records did not result in a substantial improvement to the accuracy of most models. In fact, many models performed worse on these "prewhitened" RWI records.

Additionally, climate impacts tree growth nonlinearly in the real world. For example, precipitation may only contribute to new growth until the soil is saturated or nearly saturated. Growth models often account for such issues by employing a soil-water balance term that accounts for how precipitation rate, temperature, humidity, soil properties, and conductive properties of overlying vegetation interact to impact the availability of water to plants (Stephenson 1990; Stephenson 1998; Williams et al. 2008). We did not incorporate such a variable in this study, however, because we did not know enough about the soil and vegetation properties at each site to make accurate calculations of soil-water balance.

An alternate method of dealing with nonlinear relationships between climate and ring width is to include nonlinear growth predictors into the growth equations. In a preliminary analysis where growth equations were allowed to include quadratic relationships, nonlinear relationships with precipitation were most commonly included at sites in the Southwest (SW) and West North Central (WNC) regions. Nonlinear relationships with temperature were most common in the NW region. There was no obvious commonality, however, among sites and/or species within these regions where nonlinear relationships substantially improved model performance. It therefore seemed likely that allowing for nonlinearity would lead to more harm than good by the overfitting of many RWI models. We did not allow for the incorporation of nonlinear relationships in this study.

Finally, increasing concentrations of $\mathrm{CO}_{2}$ in the atmosphere will likely have important impacts on plants, and these effects are anticipated to vary widely by 
Earth Interactions - Volume 14 (2010) • Paper No. 19 • Page 7

region and species (Ward and Strain 1999). The effect of $\mathrm{CO}_{2}$ enrichment on tree growth is difficult to identify in RWI records, however, because the concentration of atmospheric $\mathrm{CO}_{2}$ has been steadily rising throughout the industrial era without substantial interannual variability. Therefore, the decreasing radial growth rate that naturally occurs in growing trees may mask a positive growth relationship with $\mathrm{CO}_{2}$ or cause a negative growth relationship to be difficult to interpret (Gedalof and Berg 2010). The statistical standardization process used to eliminate ring-width trends associated with increasing tree size are likely to remove any long-term growth trends associated with increased atmospheric $\mathrm{CO}_{2}$. As in Williams et al. (Williams et al. 2010), we therefore made no specific effort to include the effects of the increasing atmospheric $\mathrm{CO}_{2}$ on tree growth.

\subsection{Growth response to twenty-first-century climate}

We used the PRISM climate dataset to model RWI values at each site from 1950 to 1999. This was necessary because most RWI chronologies were collected before 1999 and thus did not extend through 1999. This did not impact the results substantially because both modeled and actual mean RWI values from 1950 onward were very close to one. We then used four distinct scenarios of twenty-first-century climate to model 2050-99 RWI values. For each climate scenario, we compared the average modeled 2050-99 RWI value to that for 1950-99 and then calculated the percent change in average RWI due to climate change (Grissino-Mayer and Fritts 1995). To validate our use of modeled twentieth-century RWI values in these calculations, we repeated these calculations comparing the average of all measured, not modeled, RWI values from 1940 onward to the average of the projected RWI values one century in the future (2040 onward).

The datasets representing the first two scenarios were developed by the National Center for Atmospheric Research (NCAR) using the Community Climate System Model, version 3 (CCSM3) general circulation model (GCM). We obtained these datasets from the World Climate Research Programme's Coupled Model Intercomparison Project phase 3 multimodel dataset. The first scenario represents the Intergovernmental Panel on Climate Change (IPCC) A2 case, which assumes business-as-usual greenhouse gas emissions throughout the twenty-first century (Thomas et al. 2004). The second scenario represents the IPCC A1B case, which assumes that the rate of greenhouse gas accumulation in the atmosphere will slow after 2050 (Bernstein et al. 2007). These model datasets are gridded with $1.4^{\circ}$ spatial resolution. They are identical from 1896 through 1999 and then diverge.

We downscaled the $1.4^{\circ}$ seasonal CCSM3 climate data so they matched the measured (PRISM) 1896-1999 seasonal mean at each tree-ring site. We first upscaled the original 2.5 arc min PRISM data to the spatial resolution of the CCSM3 data by calculating the mean value of all PRISM gridded time series that fall within each CCSM3 grid cell. We adjusted each seasonal CCSM3 time series to have the same 1896-1999 mean as the corresponding upscaled PRISM time series by simply using addition or subtraction. To then downscale the adjusted CCSM3 seasonal data to represent climate at each tree-ring site, we determined the linear relationship between the upscaled $1.4^{\circ}$ PRISM data and the site-specific PRISM data using linear regression. We then used the slope and intercept terms from this 
Earth Interactions - Volume 14 (2010) - Paper No. 19 • Page 8

regression to downscale adjusted CCSM3 modeled climate data to represent modeled climate at each site.

The third climate scenario assumed that linear climate trends established in the PRISM dataset from 1896 to 2008 (113 years) will continue through 2099. The fourth scenario assumed a continuation of linear trends established from 1979 to 2008 (30 years), when warming accelerated globally. In each of these cases, time series were identical from 1896 to 2008. For 2009-99, climate values from 1909 to 1999 were adjusted to follow either the 113-yr trend (third scenario) or 30-yr trend (fourth scenario). In the cases of very strong trends in these scenarios, we did not allow seasonal precipitation during 2050-99 to become negative and we confined relative humidity values to between zero and $100 \%$.

\section{Results and discussion}

Among the 1097 ring-width models developed, 853 modeled RWI series agreed well (cross-validated $p$ value $<0.001$ ) with actual post-1895 ring-width records. To highlight regional differences, we considered nine climate regions in the continental United States defined by the National Climate Data Center. These regions are East North Central (ENC), NW, WNC, Northeast (NE), West (W), SW, Central (C), South (S), and Southeast (SE; see Figure 2 for outlines of these regions). In the SW, C, and S regions, $93 \%$ of models worked well, whereas just 53\% of models worked well in the ENC, NW, and NE regions. This is presumably because these regions are less drought prone than the SW, C, and S regions. Although the cooler and wetter NW and NE regions have more unsuccessfully modeled populations, Figures $1 \mathrm{e}-\mathrm{h}$ indicate that, within these regions, sites with unsuccessful models were not distinguishable climatically from those with successful models. Nationally, models were most often unsuccessful for white fir, California red fir, Engelmann spruce, red spruce, eastern hemlock, Jeffrey pine, and red pine. Nearly all sites where these species were sampled are cold and relatively wet. Interestingly, sites with unsuccessful models for each of these species were no cooler or wetter than those with successful models (not shown). Although these species were unsuccessfully modeled at high rates, ponderosa pine and Douglas fir had the highest number of unsuccessful models because these species were the most commonly represented species in this study. Figures 1a-d show that among populations of these species, both of which occur throughout the montane western United States, the unsuccessful models tend to be for populations at relatively cool and wet sites, often in the Pacific Northwest.

Among the 853 models that worked well, precipitation was included in $86 \%$. Relative humidity was included in $68 \%$. Of the populations sensitive to precipitation, $91 \%$ responded positively to precipitation and $79 \%$ of those sensitive to relative humidity responded positively to relative humidity. The widespread positive growth relationship with precipitation and relative humidity indicates that water balance is a common growth-limiting factor among these 853 tree populations. This is supported by the contrasting RWI relationships with daily maximum and minimum temperatures. Maximum temperature had a negative impact on growth during at least one season in $59 \%$ of the models. Just $30 \%$ of the models incorporated a negative response to minimum temperature.

The impact of drought on RWI chronologies was regionalized. Although seasonal precipitation accounted for an average of more than $30 \%$ of RWI variability 
a)

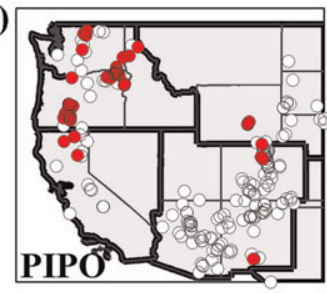

c)

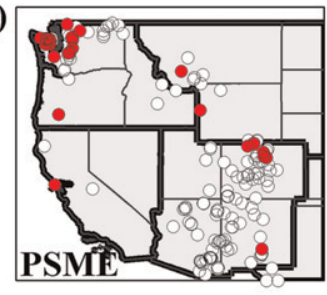

e)
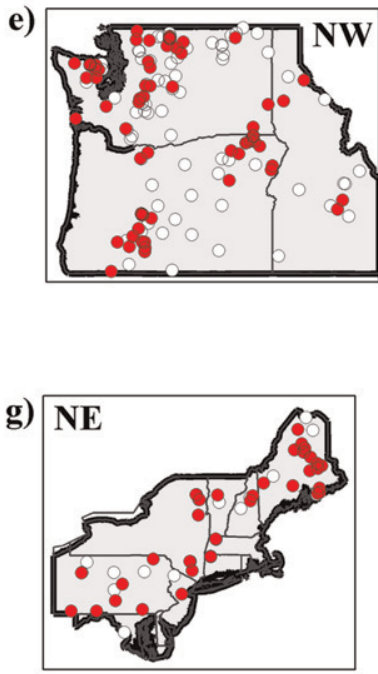
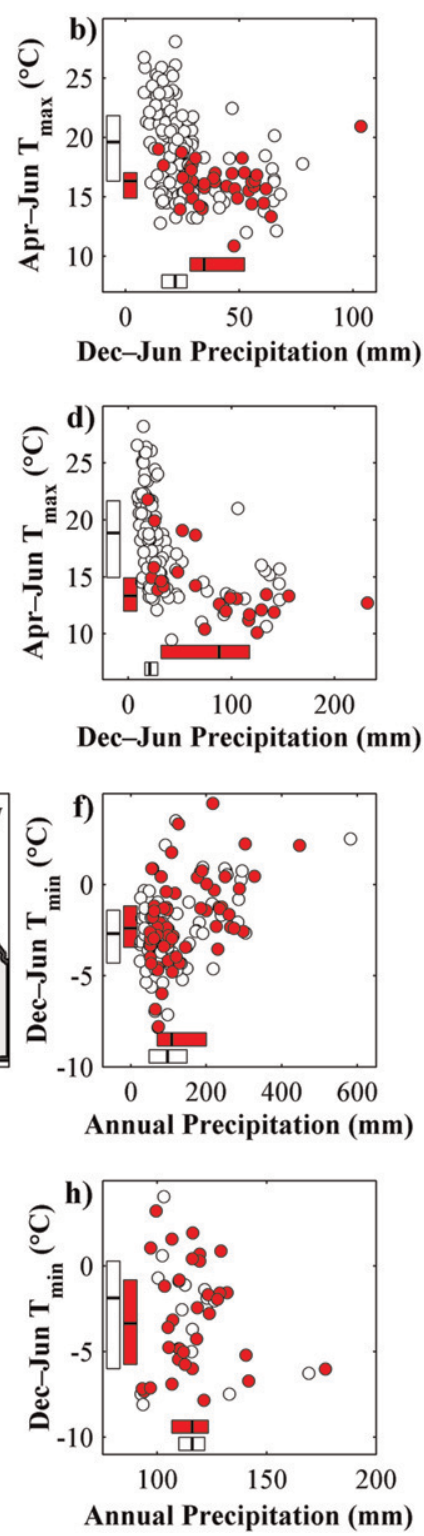

Figure 1. Locations and mean climate characteristics of sites where models worked well (white circles, cross-validated $p<0.001$ ) and sites where models did not work well (red circles): (a),(b) ponderosa pine; (c),(d) Douglas fir; $(e),(f)$ NW region; and $(g),(h)$ NE region. Bars in $(b),(d),(f),(h)$ bound quartiles of mean climate values at sites indicated by the circles of like color. Heavy lines within bars indicate median values.

at $\mathrm{SW}, \mathrm{S}$, and $\mathrm{W}$ sites, it accounted for less than $16 \%$ at $\mathrm{NW}$ and $\mathrm{NE}$ sites. The climate sensitivity section of Table 1 indicates the regional proportions of RWI records sensitive to each climate variable. Figure 2 maps how often each variable was the primary ring-width determinant in each region. 
Earth Interactions V Volume 14 (2010) - Paper No. 19 • Page 10

Table 1. Regional summaries of climate sensitivity and projected ring-width response.

\begin{tabular}{|c|c|c|c|c|c|c|c|c|c|c|c|}
\hline \multicolumn{3}{|c|}{ Region } & ENC & NW & WNC & $\mathrm{NE}$ & $\mathrm{W}$ & SW & $\mathrm{C}$ & SE & $S$ \\
\hline \multicolumn{3}{|c|}{$N$ (No. of records) } & 54 & 154 & 75 & 61 & 202 & 357 & 65 & 59 & 70 \\
\hline \multicolumn{3}{|c|}{$N_{\text {sensitive }}$} & 33 & 85 & 52 & 25 & 161 & 332 & 58 & 40 & 67 \\
\hline \multicolumn{3}{|c|}{$N_{\text {sensitive }}(\%)$} & 61 & 55 & 69 & 41 & 80 & 93 & 89 & 68 & 96 \\
\hline \multirow[t]{8}{*}{ Climate sensitivity* } & $\mathrm{PPT}^{* *}$ & $\%+$ & 91 & 52 & 75 & 52 & 80 & 86 & 72 & 75 & 78 \\
\hline & & $\%-$ & 3 & 29 & 10 & 32 & 6 & 4 & 5 & 10 & 4 \\
\hline & $T_{\max }$ & $\%+$ & 3 & 48 & 21 & 24 & 20 & 9 & 7 & 23 & 3 \\
\hline & & $\%-$ & 82 & 34 & 46 & 52 & 43 & 60 & 84 & 50 & 64 \\
\hline & $T_{\min }$ & $\%+$ & 36 & 38 & 19 & 52 & 40 & 23 & 38 & 28 & 22 \\
\hline & & $\%-$ & 21 & 38 & 42 & 32 & 17 & 28 & 14 & 23 & 24 \\
\hline & RH & $\%+$ & 61 & 36 & 42 & 40 & 47 & 65 & 36 & 43 & 49 \\
\hline & & $\%-$ & 18 & 33 & 10 & 48 & 17 & 8 & 7 & 20 & 21 \\
\hline \multirow[t]{12}{*}{ Projected $\Delta$ RWI $(\%)$} & & $\mathrm{A} 2$ & -17 & -2 & -28 & 10 & -15 & -39 & -14 & -2 & -15 \\
\hline & Mean & A1B & -14 & -2 & -24 & 6 & -10 & -27 & -10 & 1 & -10 \\
\hline & & 113-yr trend & 5 & 3 & -5 & 4 & 4 & -10 & 4 & 1 & 8 \\
\hline & & $30-\mathrm{yr}$ trend & 36 & 11 & -6 & 14 & -32 & -96 & 13 & -2 & -2 \\
\hline & & $\mathrm{A} 2$ & -8 & 22 & 5 & 24 & 1 & -14 & -5 & 17 & -1 \\
\hline & Top & A1B & -6 & 19 & 4 & 13 & 4 & -6 & -3 & 21 & 4 \\
\hline & quartile & 113-yr trend & 11 & 12 & 4 & 9 & 11 & 5 & 7 & 5 & 13 \\
\hline & & $30-\mathrm{yr}$ trend & 64 & 30 & 26 & 34 & 14 & -32 & 28 & 35 & 34 \\
\hline & & $\mathrm{A} 2$ & -28 & -27 & -49 & -8 & -32 & -62 & -31 & -27 & -31 \\
\hline & Bottom & A1B & -21 & -24 & -46 & -12 & -23 & -47 & -21 & -21 & -24 \\
\hline & quartile & $113-\mathrm{yr}$ trend & 2 & -5 & -11 & -5 & -4 & -21 & 0 & -6 & 3 \\
\hline & & $30-\mathrm{yr}$ trend & 18 & -35 & -34 & -23 & -68 & -141 & -2 & -37 & -33 \\
\hline
\end{tabular}

* Rows within the climate sensitivity section indicate regional percentages of ring-width models that incorporate each of the four climate parameters considered in this study and whether those modeled relationships were positive or negative.

** Precipitation is abbreviated as PPT.

In addition to regional differences in growth sensitivity to climate, climate change throughout the twenty-first century is expected to vary regionally (Table 2). In general, all four climate change scenarios considered in this study predict increased drought west of the Rocky Mountains, especially in the SW region, as a result of increased temperature, decreased precipitation, and decreased relative humidity. East of the Rocky Mountains, there is less agreement among the four climate scenarios. The CCSM3 scenarios project increased precipitation and temperature (though less than in the west) and decreased relative humidity, with the exception of slightly increased relative humidity on the eastern slope of the southern Appalachians. In contrast, continuation of 113-yr trends in the east would mean substantially less warming and a slight increase in relative humidity. Continuation of 30-yr trends would lead to substantially increased precipitation in the NE, nearly no daytime warming over the western slope of the southern Appalachians, and increased relative humidity throughout the regions east of the Rocky Mountains.

Figure 3 shows how forest growth is projected to change at each site in response to each of the four climate scenarios considered. The most substantial impacts on tree growth are predicted to be negative and occur in the SW because of warming and drying. Although drought sensitivity is widespread throughout the SW region, increased drought is modeled to have the greatest impact at warmer sites (Figure 4) 
a
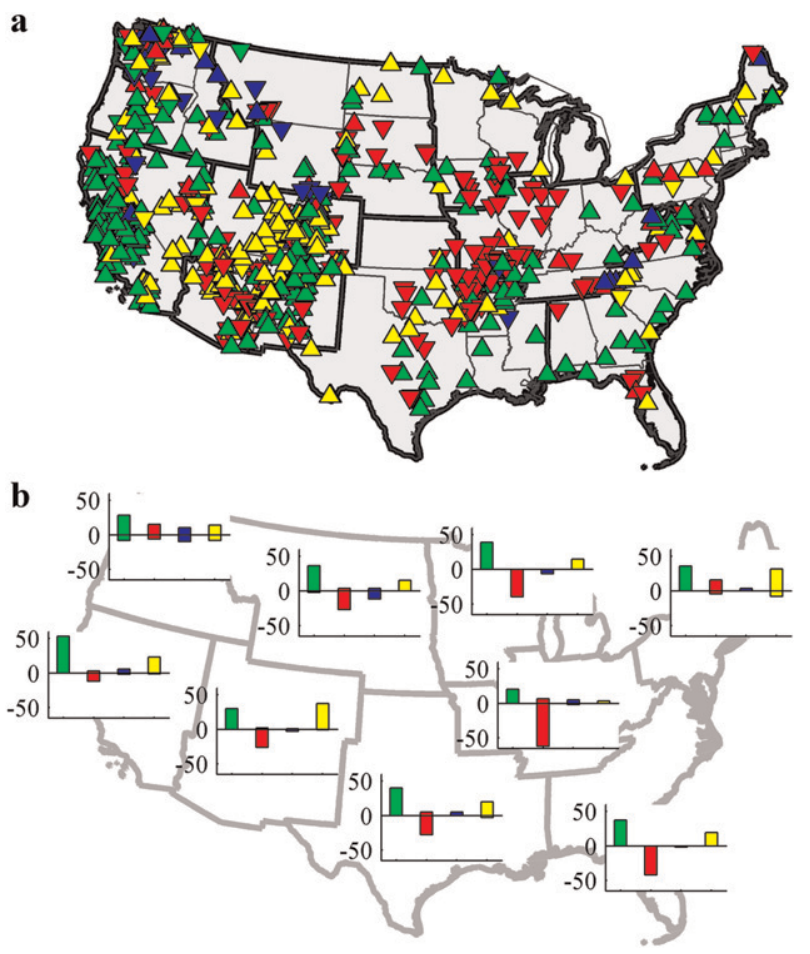

Figure 2. (a) The primary climate variable in each of the 853 growth models evaluated and its directional impact on growth. Green is precipitation, red is daily maximum temperature, blue is daily minimum temperature, and yellow is relative humidity. Triangles pointing up indicate positive relationships with tree growth. Triangles pointing down indicate negative relationships. (b) The frequency (\%) at which each of the four climate variables was the primary model variable in each region. Bars pointing up represent positive relationships with tree growth. Bars pointing down represent negative relationships.

because ring-width records from warmer sites are more sensitive to precipitation and daytime temperature than are records from cooler sites, which is consistent with the results of other case studies in the region (Adams and Kolb 2004; McDowell et al. 2008). This probably translates to a general elevation effect across the SW region, where populations growing at warm, dry lower-elevation sites are more drought sensitive than populations growing at cooler, wetter higher-elevation sites. This is similar to the findings of Williams et al. (Williams et al. 2010), but here the SW region comprises a substantially larger geographic region. The SW forests evaluated in this study least likely to suffer from increased drought are the highest-elevation "sky island" forests (Lomolino et al. 2006) because they showed the least sensitivity to drought.

In the NW region, where drought is a less common growth-limiting factor, we observed an interesting relationship between tree growth and daily maximum temperature. Although the 154 ring-width records from the NW region are generally not as sensitive to climate variability as those in the SW, 91 of the NW 
Earth Interactions Volume 14 (2010) - Paper No. 19 • Page 12

Table 2. Regional summaries of projected climate change, considering four scenarios (projected 2050-99 annual mean minus measured 1950-99 annual mean).

\begin{tabular}{llrrrrrrrrr}
\hline & Region & ENC & NW & WNC & NE & W & SW & C & S & SE \\
\hline$\Delta$ PPT & A2 & 84 & -1 & 79 & 84 & -73 & -11 & 91 & 83 & 57 \\
& A1B & 89 & 20 & 78 & 79 & -16 & 19 & 103 & 112 & 75 \\
$(\mathrm{~mm})$ & 113-yr trend & 76 & 34 & 22 & 88 & 47 & 19 & 72 & 46 & 108 \\
& $30-$ yr trend & 23 & -63 & 24 & 350 & -203 & -217 & 29 & -218 & -55 \\
$\Delta T_{\max }$ & A2 & 4.1 & 4.1 & 4.0 & 3.5 & 4.1 & 4.4 & 3.7 & 2.9 & 3.5 \\
& A1B & 3.4 & 3.6 & 3.4 & 3.0 & 3.5 & 3.6 & 2.9 & 2.2 & 2.8 \\
$\left({ }^{\circ} \mathrm{C}\right)$ & 113-yr trend & 0.3 & 0.5 & 0.7 & 0.7 & 0.7 & 0.7 & -0.2 & 0.0 & -0.1 \\
& 30-yr trend & 1.6 & 2.5 & 1.8 & 1.9 & 2.4 & 3.2 & 1.5 & 0.7 & 1.3 \\
$\Delta T_{\min }$ & A2 & 4.8 & 4.2 & 4.5 & 4.2 & 4.0 & 4.5 & 4.1 & 3.3 & 3.8 \\
& A1B & 4.0 & 3.8 & 3.9 & 3.5 & 3.5 & 3.8 & 3.3 & 2.6 & 3.0 \\
$\left({ }^{\circ} \mathrm{C}\right)$ & 113-yr trend & 0.9 & 1.2 & 1.3 & 0.9 & 1.1 & 1.1 & 0.2 & -0.1 & 0.2 \\
& 30-yr trend & 3.4 & 3.8 & 3.6 & 3.2 & 2.9 & 3.3 & 3.3 & 2.2 & 2.2 \\
$\Delta \mathrm{RH}$ & A2 & -1.7 & -1.8 & -1.4 & -0.7 & -2.0 & -2.8 & -1.2 & -0.2 & 55.0 \\
& A1B & -1.0 & -1.8 & -0.7 & -0.7 & -1.3 & -1.7 & -0.2 & 0.4 & -0.5 \\
$(\%)$ & 113-yr trend & 1.6 & 0.2 & 1.1 & 1.6 & 0.0 & 0.0 & 1.4 & 1.2 & 2.0 \\
& 30-yr trend & 13.2 & -3.4 & 5.5 & 8.8 & -10.4 & -13.0 & 8.6 & 10.1 & 9.1 \\
\hline
\end{tabular}

growth models indicate sensitivity to maximum daily temperature during at least one season. Of these, 59 (representing 11 species) grow within the Cascade Mountain Range. Those growing at cooler sites tended to respond positively to increased daytime temperature, whereas those growing at warmer sites tended to respond negatively. This was clearest considering RWI relationships with average daily maximum temperature from late spring through summer, particularly June through August (Figure 5a). A similar trend was observed by Ettl and Peterson (Ettl and Peterson 1995) among populations of Abies lasiocarpa in the Olympic Mountain Range of Washington. Here, the threshold between positive and negative temperature response appears to occur when the June-August mean daily maximum temperature surpasses roughly $20^{\circ} \mathrm{C}$. At cold sites, positive relationships with temperatures may represent sensitivity to short growing seasons due to high springtime snowpacks and low temperatures, as was hypothesized by Peterson et al. (Peterson et al. 2002). At warm sites, negative relationships between with temperature may be due to drought because these sites receive less precipitation. Figure 5b shows that growth at the warm, dry sites is positively correlated with annual precipitation. These relationships are weak or negative at the cool, wet sites. This is consistent with the findings of Ettl and Peterson (Ettl and Peterson 1995) and Peterson et al. (Peterson et al. 2002).

We predict that large temperature increases would cause many Cascade populations to shift from temperature- to moisture-limited growth at sites where the June-August daily maximum temperatures are close to $20^{\circ} \mathrm{C}$, roughly between 1000 and $1500 \mathrm{~m}$ above mean sea level (MSL; PRISM dataset). The exact temperature threshold and growth sensitivity on either side of the threshold should vary according to species and site water balance. Among the 59 temperature-sensitive Cascade populations, mountain hemlock [Tsuga mertensiana (Bong.) Carr.], Douglas-fir [Pseudotsuga menziesii (Mirb.) Franco], and ponderosa pine (Pinus ponderosa Dougl. ex Laws) may experience substantially altered growth responses to warming. These populations grow near the $20^{\circ} \mathrm{C}$ summertime temperature threshold and their sensitivities to temperature and precipitation appear to be 

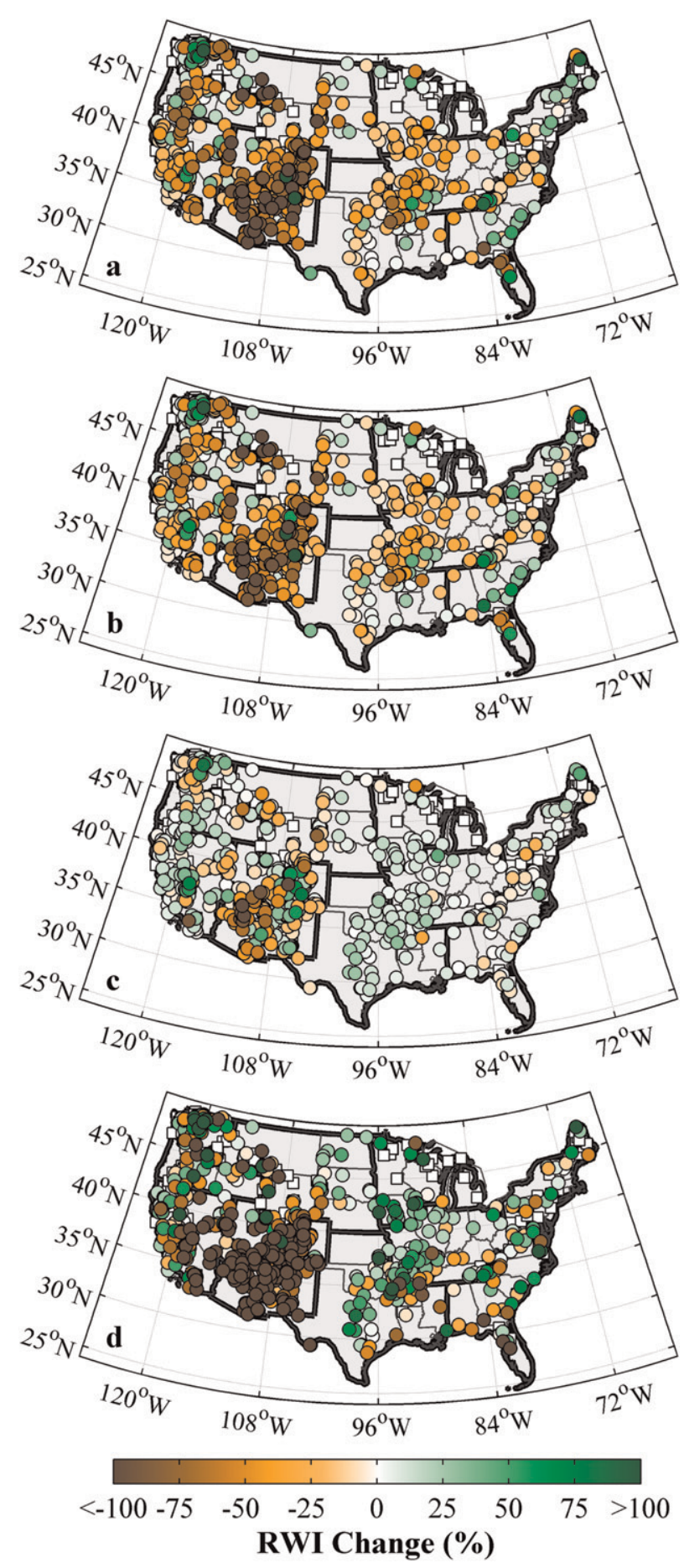

Figure 3. Modeled percentage change in average tree RWI between the periods of 2050-99 and 1950-99. Climate scenarios were the (a) IPCC A2 and (b) IPCC AIB scenarios from the NCAR CCSM3 and the continuation of linear climate trends established from (c) 1896-2008 and (d) 1979-2008 climate data. White squares indicate sites where the growth predictors could not accurately model RWI values. 


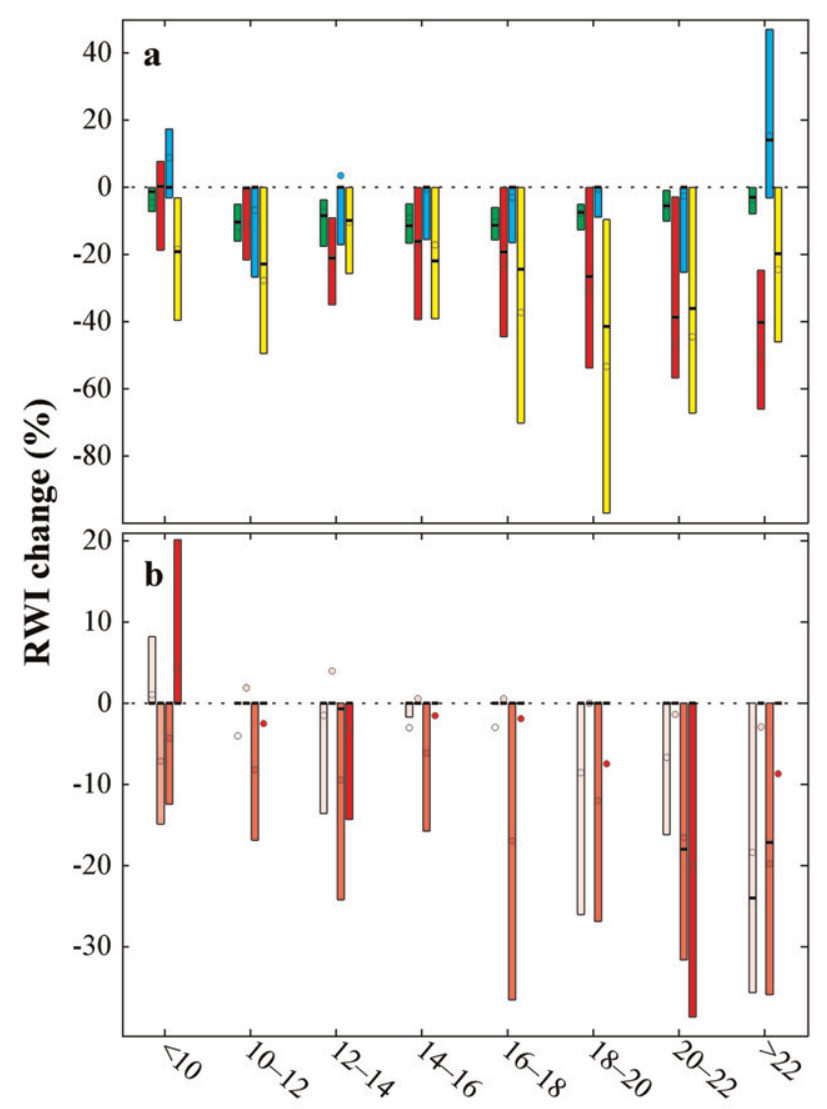

Mean Daily $\mathrm{T}_{\text {max }}\left({ }^{\circ} \mathrm{C}\right)$

Figure 4. Box plots of projected change in RWI in SW populations given hypothetical increases in drought conditions. (a),(b) Box plots are binned by mean daily maximum temperature. In (a), growth projections are in response to $25 \%$ less precipitation (green bars), $4^{\circ} \mathrm{C}$ warmer daily maximum temperature (red bars), $4^{\circ} \mathrm{C}$ warmer daily minimum temperature (blue bars), and mean relative humidity minus $15 \%$ (yellow bars). In (b), growth projections are in response to seasonal increases in daily maximum temperature of $4^{\circ} \mathrm{C}$. From lightest to darkest red, seasons are fall, winter, spring, and summer. Horizontal black lines in all box plots indicate median values. Circles indicate mean values. Boxes bound the inner quartiles.

variable. Notably, we are not the first to use tree-ring records to project a nonlinear response of mountain hemlock to temperature change in the Cascade Mountain Range (Peterson and Peterson 2001).

Although interesting stories about forest growth and climate were readily apparent in the western United States, robust conclusions were more elusive for regions east of the Rocky Mountains. This is partly because CCSM3 climate projections (scenarios 1 and 2) for the regions east of the Rocky Mountains do not agree well with projections based upon climate trends established during the past 113 or 30 years (scenarios 3 and 4 , respectively). The most substantial differences between the 

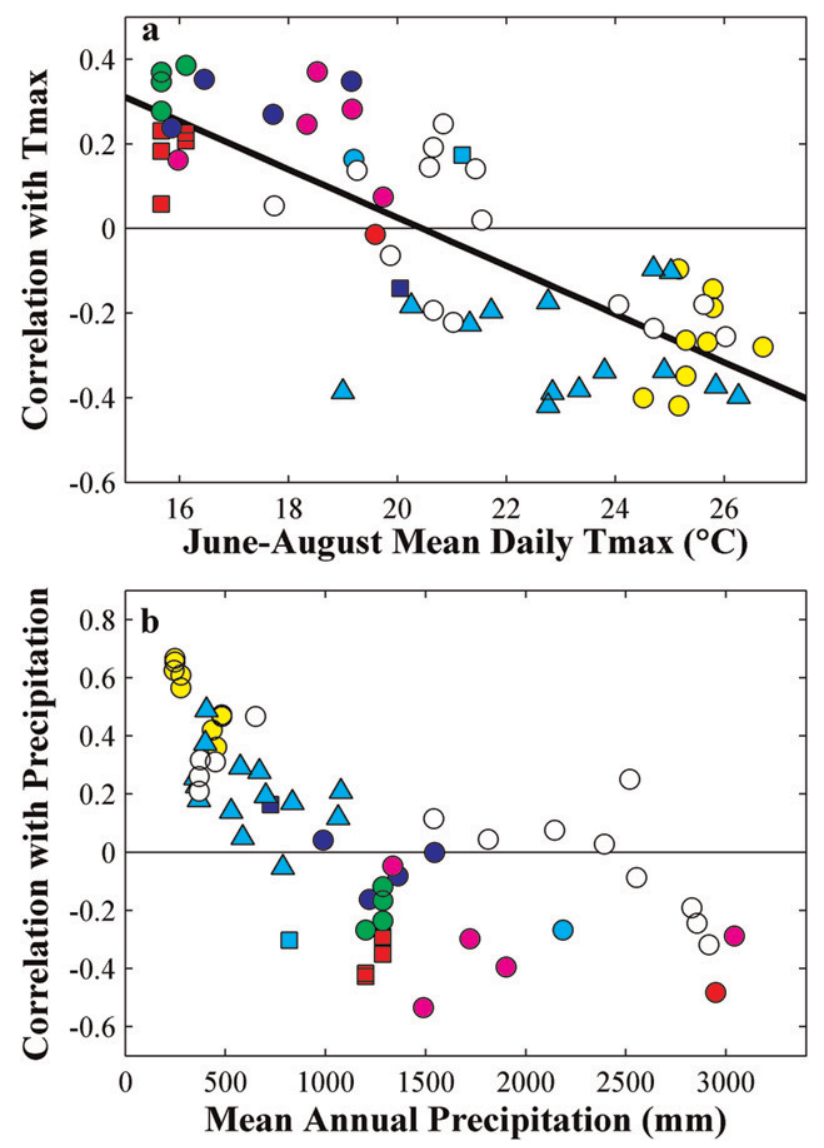

Figure 5. Correlation statistics for 59 populations growing in the Cascade Mountain Range of the NW region that are modeled to be sensitive to temperature variability. (a) Correlation between annual RWI and mean June-August daily maximum temperature, plotted against daily June-August maximum temperature averaged from 1895 to 2008. (b) Correlations between annual RWI and annual October-September precipitation, plotted against October-September precipitation averaged from 1895 to 2008. Each color represents a unique genus. Unique shapes of the same color represent species of the same genus. Red: circles $=$ Abies amabilis, squares $=A$. lasiocarpa. Yellow: circles = Juniperus occidentalis. Blue: circles = Larix lyalli, squares $=$ L. occidentalis. Green: circles = Picea engelmannii. Cyan: circles $=$ Pinus albicaulis, squares $=$ Pinus Contorta, triangles $=$ P. ponderosa. White: circles $=$ Pseudotsuga menziesii. Magenta: circles = Tsuga mertensiana.

CCSM3- and PRISM-based growth models occurred in the $\mathrm{S}$ and $\mathrm{C}$ regions. In the Ozark Mountain Range and Mississippi River Valley, for example, CCSM3 climate change scenarios predict increased temperature and decreased relative humidity, resulting in a large swath of decreased growth (Figures 3a,b) almost entirely represented by oak populations. Among oak populations sampled within these regions, the $\mathrm{A} 2$ and $\mathrm{A} 1 \mathrm{~B}$ climate scenarios are projected to cause decreased growth rates at 
Earth Interactions - Volume 14 (2010) • Paper No. 19 • Page 16

$90 \%$ and $84 \%$ of sites, respectively. Twentieth-century temperatures did not rise in these regions, however, and relative humidity actually increased at many sites. Growth models based upon trends established during the twentieth century predict increased tree growth for the majority of these oak populations (Figures 3c,d).

\section{Conclusions}

As discussed in McKenzie et al. (McKenzie et al. 2001) and Williams et al. (Williams et al. 2010), it is not valid to directly extrapolate the results presented here to all forests in the continental United States because the RWI chronologies do not come from random tree populations. Many sites (and individual trees) were sampled because they were in topographic and ecological conditions likely to promote climatic responsiveness (particularly drought). Therefore, many of the RWI records may overrepresent climate sensitivity. On the other hand, ring-width data may underrepresent climate sensitivity because long-lived trees are commonly sampled for tree-ring studies. Long-lived trees have typically survived repeated periods of nonideal growth conditions, particularly at drought-prone sites, so they may be more drought resilient than unsampled trees that died relatively young because of poor climate conditions (McDowell et al. 2010). We still do not know how tree-ring estimates of growth may correlate with more representative forest growth estimates like the Forest Inventory Analysis and satellite data because these estimates are too new to provide sufficient temporal overlap with tree-ring chronologies. For the time being, it seems wise to look for lessons in the data available. In interpreting these lessons, it is important to be conservative. Extrapolating linear relationships with climate into a future with climate change is bound to lead to errors because relationships between tree growth and climate are nonlinear. Notably, the nonstationary relationships between ring widths and climate in the NW suggested here and elsewhere have implications for the fields of dendroecology and dendroclimatology. Nonstationarity in growth-climate relationships surely causes inaccuracy when using RWI-climate relationships to project future growth or reconstruct past climate.

Interpreting conservatively, this study discovered significant statistical relationships between tree-ring widths and seasonal climate for 853 tree populations in the continental United States. Given the high level of regional agreement among RWI response to climate, it is likely that many of the large-scale spatial growth patterns presented in this analysis are at least qualitatively representative of true regional patterns in forest response to climate variability. As in Williams et al. (Williams et al. 2010), we predict that the region likely to be most affected by climate in coming decades is the drought-prone SW, in agreement with the satellitederived observations made by Hicke et al. (Hicke et al. 2002). Interestingly, recent global analyses do not highlight the SW United States forests as having undergone substantial change in recent years (Gonzalez et al. 2010; Hansen et al. 2010). Williams et al. (Williams et al. 2010), on the other hand, used satellite-derived and aerial survey data to estimate that up to $18 \%$ of southwestern forest area experienced mortality because of bark beetles and wildfire from 1997 through 2008, suggesting that the global analyses may overlook forest response to drought in the SW United States because of low spatial resolution.

Although there is still uncertainty regarding future precipitation within the SW, models consistently predict warming and decreasing relative humidity. These pro- 
jected changes are expected to lead to less water availability, even in the potential case of a modest increase in precipitation (Seager and Vecchi 2010). Our models indicate that warming and decreased water availability will generally have the largest impacts on SW forests growing at warm, low-elevation sites. This inverse relationship between elevation and sensitivity to drought was also documented in the SW by Allen and Breshears (Allen and Breshears 1998), Mueller et al. (Mueller et al. 2005), and van Mantgem et al. (van Mantgem et al. 2009). Additionally, we know that forest ecotones were generally lower in elevation throughout the SW during the last glacial period when summer temperatures were several degrees lower (Malde 1964). Two processes important in dictating forest ecotones and distributions in the SW are wildfires and bark-beetle outbreaks, both of which are positively associated with drought conditions (Swetnam and Betancourt 1990; Swetnam and Betancourt 1998; McKenzie et al. 2004; Hicke et al. 2006; Westerling et al. 2006).

In contrast to the SW, increased growth is predicted for the majority of forest populations considered from the wet and cool NW and NE regions. Populations sampled within the SE are projected to be impacted the least because of relatively minimal projected climate change. Interestingly, Hansen et al. (Hansen et al. 2010) indentified the southeast United States as having lost 5\%-10\% of its forest cover from 2000 to 2005, among the highest rates of loss globally.

To conclude, we discovered a number of insights about how twentieth-century climate variability impacted forest growth at many sites within the continental United States. Although growth-climate relationships are not truly linear, many of those observed during the twentieth century will continue to be relevant throughout the coming century. It is interesting that projected changes in growth by the end of the twenty-first century are so similar for two CCSM3 climate scenarios, even though the A1B scenario assumes a stabilization of greenhouse emissions after 2050 whereas the A2 scenario assumes a continual rise. This implies that much of the projected growth change is attributed to emissions that are expected to take place before 2050. In other words, many forests in the continental United States are projected to be substantially impacted by climate change in the next several decades, even if we curb global greenhouse gas emissions in step with the more optimistic A1B scenario.

Acknowledgments. We thank the many people who collected, cross dated, measured, and archived the numerous tree-ring chronologies that we accessed from the ITRDB. We also thank H. Grissino-Mayer and L. Laforest for their contribution of a chronology from Great Smokey Mountains National Park; S. Chaney, C. Cowan, and K. McEachern for their help in acquiring a chronology from Channel Islands National Park; and J. Burns and R. Adams for their knowledge and assistance in cross dating. Insights from J. Hicke and N. Stephenson greatly improved the quality of the manuscript. The methodology was also impacted by previous work with C. Allen, T. Swetnam, and C. Millar.

\section{References}

Adams, H. D., and T. E. Kolb, 2004: Drought responses of conifers in ecotone forests of northern Arizona: Tree ring growth and leaf $\delta^{13}$ C. Oecologia, 140, 217-225.

Allen, C. D., and D. D. Breshears, 1998: Drought-induced shift of a forest-woodland ecotone: Rapid landscape response to climate variation. Proc. Natl. Acad. Sci. USA, 95, 14 83914842. 
Earth Interactions - Volume 14 (2010) • Paper No. 19 • Page 18

_ , and Coauthors, 2010: A global overview of drought and head-induced tree mortality reveals emerging climate change risks for forests. For. Ecol. Manage., 259, 660-684.

Babbage, C., 1838: The Ninth Bridgewater Treatise: A Fragment. J. Murray, 284 pp.

Bernstein, L., and Coauthors, 2007: Climate Change 2004: Synthesis Report. Cambridge University Press, 104 pp.

Boisvenue, C., and S. W. Running, 2006: Impacts of climate change on natural forest productivityEvidence since the middle of the 20th century. Global Change Biol., 12, 862-882.

Breshears, D. D., and Coauthors, 2005: Regional vegetation die-off in response to global-changetype drought. Proc. Natl. Acad. Sci. USA, 102, 15 144-15 148.

Cook, E. R., K. Briffa, S. Shiyatov, and V. Mazepa, 1990: Tree-ring standardization and growthtrend estimation. Methods of Dendrochronology: Applications in the Environmental Sciences, E. R. Cook and L. A. Kairiukstis, Eds., Kluwer Academic, 104-123.

Davis, M. B., and R. G. Shaw, 2001: Range shifts and adaptive responses to quaternary climate change. Science, 292, 673-679.

Di Luzio, M., G. L. Johnson, C. Daly, J. K. Eischeid, and J. G. Arnold, 2008: Constructing retrospective gridded daily precipitation and temperature datasets for the conterminous United States. J. Appl. Meteor., 47, 475-497.

Douglass, A. E., 1909: Weather cycles in the growth of big trees. Mon. Wea. Rev., 37, 225-237.

Ettl, G. J., and D. L. Peterson, 1995: Growth response of subalpine fir (Abies lasiocarpa) to climate in the Olympic Mountains, Washington, USA. Global Change Biol., 1, 213-230.

Fischer, D. T., C. J. Still, and A. P. Williams, 2009: Significance of summer fog and overcast for drought stress and ecological functioning of coastal California endemic plant species. J. Biogeography, 36, 783-799.

Fritts, H. C., 1976: Tree Rings and Climate. Academic Press, 567 pp.

Gedalof, Z., and A. A. Berg, 2010: Tree ring evidence for limited direct $\mathrm{CO}_{2}$ fertilization of forests over the 20th century. Global Biogeochem. Cycles, 24, GB3027, doi:10.1029/2009GB003699.

Gonzalez, P., R. P. Neilson, J. M. Lenihan, and R. J. Drapek, 2010: Global patterns in the vulnerability of ecosystems to vegetation shifts due to climate change. Global Ecol. Biogeography, 19, 755-768, doi:10.1111/j.1466-8238.2010.00558.x.

Gosz, J. R., 1992: Gradient analysis of ecological change in time and space: Implications for forest management. Ecol. Appl., 2, 248-261.

Grissino-Mayer, H. D., and H. C. Fritts, 1995: Dendroclimatology and dendroecology in the Pinaleño Mountains. Storm over a Mountain Island: Conservation Biology and the Mount Graham Affair, R. Hoffman and C. Istock, Eds., The University of Arizona Press, 100-120.

— , R. L. Holmes, and H. C. Fritts, 1993: International tree-ring data bank program library. Laboratory of Tree-Ring Research, University of Arizona. [Available online at http://www. ncdc.noaa.gov/paleo/treering.html.]

Hansen, M. C., S. V. Stehman, and P. Potapov, 2010: Quantification of global gross forest cover loss. Proc. Natl. Acad. Sci. USA, 107, 8650-8655.

Hicke, J. A., G. P. Asner, J. T. Randerson, C. Tucker, S. Los, R. Birdsey, J. C. Jenkins, and C. Field, 2002: Trends in North American net primary productivity derived from satellite observations, 1982-1998. Global Biogeochem. Cycles, 16, 1018-1039.

— J. J. Logan, J. Powell, and D. S. Ojima, 2006: Changing temperatures influence suitability for modeled mountain pine beetle (Dendroctonus ponderosae) outbreaks in the western United States. J. Geophys. Res., 111, G02019, doi:10.1029/2005JG000101.

Holland, M., P. G. Risser, and R. J. Naiman, 1991: Ecotones: The Role of Landscape Boundaries in the Management and Restoration of Changing Environments. Chapman \& Hall, 142 pp.

Holman, M. L., and D. L. Peterson, 2006: Spatial and temporal variability in forest growth in the Olympic Mountains, Washington: Sensitivity to climatic variability. Can. J. For. Res., 36, 92-104.

Hughes, M. K., T. W. Swetnam, and H. Diaz, 2009: Dendroclimatology: Progress and Prospects. Vol. 11, Developments in Paleoenvironmental Research, Springer, 340 pp. 
Earth Interactions - Volume 14 (2010) • Paper No. 19 • Page 19

Innes, J. L., 1991: High-altitude and high-latitude tree growth in relation to past, present and future global climate change. Holocene, 1, 168-173.

Lapenis, A., A. Shvidenko, D. Shepaschenko, S. Nilsson, and A. Aiyyer, 2005: Acclimation of Russian forests to recent changes in climate. Global Change Biol., 11, 2090-2102.

Lomolino, M. V., B. R. Riddle, and J. H. Brown, 2006: Biogeography. 3rd ed. Sinauer Associates, $560 \mathrm{pp}$.

Malde, H. E., 1964: Environment and man in arid. Amer. Sci., 145, 123-129.

McDowell, N. G., and Coauthors, 2008: Mechanisms of plant survival and mortality during drought: Why do some plants survive while others succumb to drought? New Phytol., 178, 719-739.

— C. D. Allen, and L. Marshall, 2010: Growth, carbon-isotope discrimination, and droughtassociated mortality across a Pinus ponderosa elevational transect. Global Change Biol., 16, 399-415.

McKenzie, D., A. E. Hessl, and D. L. Peterson, 2001: Recent growth of conifer species of western North America: Assessing spatial patterns of radial growth trends. Can. J. For. Res., 31, 526538.

— Z Z. Gedalof, D. L. Peterson, and P. Mote, 2004: Climatic change, wildfire, and conservation: Wildfire and conservation in the western United States. Conserv. Biol., 18, 890-902.

Meko, D., and D. A. Graybill, 1995: Tree-ring reconstruction of upper Gila River discharge. Water Resour. Bull., 31, 605-616.

Michaelsen, J., 1987: Cross-validation in statistical climate forecast models. J. Appl. Meteor., 26, $1589-1600$.

Mueller, R. C., C. M. Scudder, M. E. Porter, R. T. Trotter III, C. A. Gehring, and T. G. Whitham, 2005: Differential tree mortality in response to severe drought: Evidence for long-term vegetation shifts. J. Ecol., 93, 1085-1093.

Nakawatase, J. M., and D. L. Peterson, 2006: Spatial variability in forest growth-climate relationships in the Olympic Mountains, Washington. Can. J. For. Res., 36, 77-91.

Overpeck, J. T., D. Rind, and R. Goldberg, 1990: Climate-induced changes in forest disturbance and vegetation. Nature, 343, 51-53.

Peterson, D. W., and D. L. Peterson, 2001: Mountain hemlock growth responds to climatic variability at annual and decadal time scales. Ecology, 82, 3330-3345.

,-- , and G. J. Ettl, 2002: Growth responses of subalpine fir to climatic variability in the Pacific Northwest. Can. J. For. Res., 32, 1503-1517.

Pitelka, L. F., 1997: Plant migration and climate change. Amer. Sci., 85, 464-473.

Purves, D. W., 2009: The demography of range boundaries versus range cores in eastern US tree species. Proc. Biol. Sci., 276, 1477-1486.

Risser, P. G., 1995: The status of the science examining ecotones. Bioscience, 45, 318-325.

Root, T. L., J. T. Price, K. R. Hall, S. H. Schneider, C. Rosenzweig, and J. A. Pounds, 2003: Fingerprints of global warming on wild animals and plants. Nature, 421, 57-60.

Running, S. W., R. R. Nemani, F. A. Heinsch, M. Zhao, M. Reeves, and H. Hashimoto, 2004: A continuous satellite-derived measure of global terrestrial primary production. Bioscience, $\mathbf{5 4}$, 547-560.

Sala, O. E., and Coauthors, 2000: Global biodiversity scenarios for the year 2100. Science, 287, $1770-1774$.

Seager, R., and G. A. Vecchi, 2010: Greenhouse warming and the 21st century hydroclimate of southwestern North America. Proc. Natl. Acad. Sci. USA, 107, 21 277-21 282.

Stephenson, N. L., 1990: Climatic control of vegetation distribution: The role of the water balance. Amer. Nat., 135, 649-670.

_ 1998: Actual evapotranspiration and deficit: Biologically meaningful correlates of vegetation distribution across spatial scales. J. Biogeography, 25, 855-870.

Swetnam, T. W., and J. L. Betancourt, 1990: Fire-Southern Oscillation relations in the southwestern United States. Science, 249, 1017-1020. 
— bility in the American Southwest. J. Climate, 11, 3128-3147.

Thomas, C. D., and Coauthors, 2004: Extinction risk from climate change. Nature, 427, 145148.

Van de Ven, C. M., S. B. Weiss, and W. G. Ernst, 2007: Plant species distributions under present conditions and forecasted for warmer climates in an arid mountain range. Earth Interactions, 11. [Available online at http://EarthInteractions.org.]

van Mantgem, P. J., and Coauthors, 2009: Widespread increase of tree mortality rates in the western United States. Science, 323, 521-524.

Walther, G.-R., and Coauthors, 2002: Ecological responses to recent climate change. Nature, 416, 389-395.

Ward, J. K., and B. R. Strain, 1999: Elevated $\mathrm{CO}_{2}$ studies: Past, present and future. Tree Physiol., 19, 211-220.

Westerling, A. L., H. G. Hidalgo, D. R. Cayan, and T. W. Swetnam, 2006: Warming and earlier spring increase western US forest wildfire activity. Science, 313, 940-943.

Williams, A. P., C. J. Still, D. T. Fischer, and S. W. Leavitt, 2008: The influence of summertime fog and overcast clouds on the growth of a coastal Californian pine: A tree-ring study. Oecologia, 156, 601-611.

— C. D. Allen, C. I. Millar, T. W. Swetnam, J. Michaelsen, C. J. Still, and S. L. Leavitt, 2010: Forest responses to increasing aridity and warmth in the southwestern United States. Proc. Natl. Acad. Sci. USA, 107, 21 289-21 294.

Earth Interactions is published jointly by the American Meteorological Society, the American Geophysical Union, and the Association of American Geographers. Permission to use figures, tables, and brief excerpts from this journal in scientific and educational works is hereby granted provided that the source is acknowledged. Any use of material in this journal that is determined to be "fair use" under Section 107 or that satisfies the conditions specified in Section 108 of the U.S. Copyright Law (17 USC, as revised by P.IL. 94553) does not require the publishers' permission. For permission for any other from of copying, contact one of the copublishing societies. 